Побудовано математичну модель фільтраційної консолідації тіла греблі з водоводом ізоною вимиву в двовимірному випадку. Враховано вплив техногенних факторів. Розроблено комп'ютерну програму для автоматизації розрахунків чисельного розв'язання крайової задачі безсітковим методом радіальних базисних функцій. Проведено ряд числових експериментів $i$ здійснений їх аналіз

Ключові слова: гідроенергетика, проблема фільтраційної консолідації, осмотичні явища, вільна поверхня, об'єктно-орієнтоване програмування

$\square$

Построена математическая модель фильтрационной консолидации тела плотины с водоводом и зоной размыва в двумерном случае. Учтено влияние техногенных факторов. Разработана компьютерная программа для автоматизации расчетов иисленного решения краевой задачи бессеточным методом радиальных базисных функиий. Проведен ряд числовых экспериментов и осуществлен их анализ

Ключевые слова: гидроэнергетика, проблема фильтрационной консолидащии, осмотические явления, свободная поверхность, объектно-ориентированное программирование
口

\section{UDC 519.61/.64:627.05 \\ DOI: 10.15587/1729-4061.2017.98712 \\ MATHEMATICAL \\ MODELING AND \\ COMPUTER SIMULATION OF THE FILTRATION PROCESSES IN EARTH DAMS}

N. Iva n c h u k

Assistant*

E-mail: natasha_medvid@mail.ru

P. M a r t y n y u k

Doctor of Technical Sciences, Associate Professor*

E-mail: p.m.martyniuk@nuwm.edu.ua

T. T s v e t k o va

$\mathrm{PhD}$, Associate Professor*

E-mail: t.p.tsvetkova@nuwm.edu.ua

O. M i chut a

$\mathrm{PhD}$, Associate Professor*

E-mail: o.r.michuta@nuwm.edu.ua

*Department of Applied Mathematics

National University of

Water and Environmental Engineering

Soborna str., 11, Rivne, Ukraine, 33028

\section{Introduction}

The languages of object-oriented programming (OOP) have been very popular recently with software developers. This is due to the fact that they allow the use of the advantages of object-oriented approach not only at the stages of design and construction of software systems, but also at the stages of their implementation, testing, and support.

The ideas of OOP, when certain mathematical structures are described by classes and objects, and the operations over structures (differentiation, integration, etc.) as well as the interaction between them is expressed through the methods of classes, have been widely applied in the programming of numerical methods of mathematical physics.

Numerical solution of boundary problems by grid methods (such as the finite element method) is realized in special software packages that are divided into commercial and free. Most of them can run on multiple operating systems.

Since at present there are no packages of application software for solving the boundary problems by grid-free methods, the purpose of present work is to propose some ideas of OOP for the software implementation of algorithms of one of such methods. This is executed on the example of a mathematical model for the filtration consolidation of earth dam with a conduit.

The experience of the Ukrainian and foreign dam construction reveals a lot of accidents and damage of earth dams associated with the existence of water conduits in the body of a dam. The presence in the body of an earth dam of conduits significantly impacts the nature of filtration in the near-pipe zone both at proper operation of a conduit and especially when it is damaged. However, conducting field experiments during design of the specified hydrotechnical constructions (HTC) may require significant volumes of financial resources. Therefore, the prediction of behavior of HTC is sometimes more expedient to perform by the means of mathematical modeling and computer simulation. This will make it possible not to conduct field experiments and to prevent the negative consequences of possible accidents.

\section{Literature review and problem statement}

The issue of destruction of the earth material of a dam is very important because it implies the economic, environmental and humanitarian threat. Paper [1] indicated that half of the accidents on the earth dams is related specifically to the filtration destruction.

There are statistics about the incidents and accidents on the earth dams that are associated with significant losses of material resources and, most importantly, human victims [2]. That is why, predicting the HTC operation is more expedient to conduct by the toolss of mathematical and computer modeling.

Mathematical modeling of the processes of filtration consolidation in soils taking into account the effect of heatsalt transfer was examined in article [3]. However, it did not consider the presence of a conduit in the body of the dam and a possible zone of erosion. A two-dimensional problem on the contact erosion of soil based on an earth dam was also 
explored in paper [4], but it did not take into account the impact of anthropogenic factors.

Mathematical models of the interconnected processes of filtration consolidation, filtration destruction of soils and the effect of heat-mass transfer were built and reviewed, for example, in article [5]. However, this work examined only the processes of contact erosion of soils and did not address the processes in earth dams with engineering inclusions (water conduits), moreover, it did not take into account the existence of erosion zone (washout) of soil due to a damage in a conduit. The use of RBF methods for numerical solution of mathematical models of the interrelated processes of seepage consolidation taking into account the influence of heat-salt transfer was described in paper [6]. However, the issue of data structure that were used in the practical implementation of this method was not dealt with in the indicated paper. Mathematical modeling of the process of salt transfer at filtration and moisture transfer in the case of moistening the saturated-unsaturated ground array that contains drain was presented in article [7].

Let us consider a two-dimensional problem of filtration consolidation in the body of an earth dam whose profile is shown in Fig. 1. A conduit splits the dam into regions: region $\Omega_{1}$ with boundaries $\Gamma_{6}, \Gamma_{4}, \Gamma_{2}, \Gamma_{1}$ and free surface $\Gamma_{0}$ and region $\Omega_{2}$ with boundaries $\Gamma_{3}, \Gamma_{7}, \Gamma_{5}, \Gamma_{9}$. Erosion zone is the region $\Omega_{3}$ with boundaries $\Gamma_{12}, \Gamma_{11}$. Region $\Omega_{4}$ is the area above the free surface.

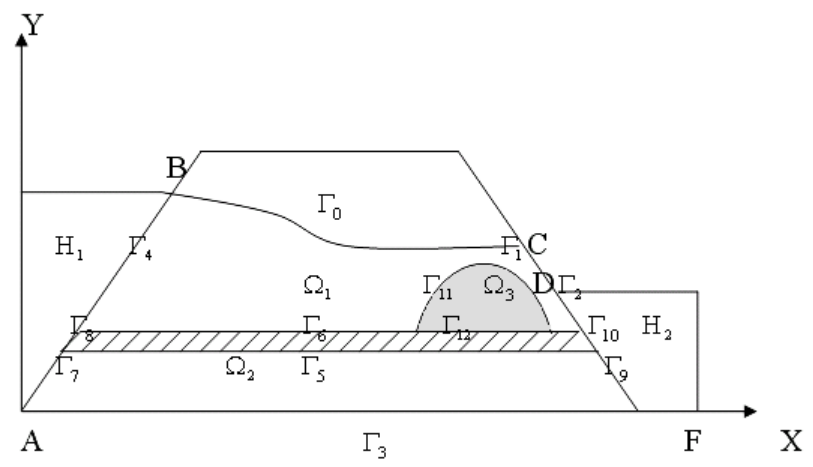

Fig. 1. Profile of the body of an earth dam with a conduit and an erosion zone

We shall make the following simplifying assumptions:

1) erosion zone is fixed at present and does not change its position and shape over time;

2) the Laplace equation holds for the heads in the erosion zone.

Then the mathematical model of a two-dimensional problem on the filtration consolidation of the body of an earth dam with a conduit and erosion zone, considering the creep of soil skeleton and the heat-salt transfer, can be described by the following boundary problem:

- filtration consolidation equation [3]

$$
\begin{aligned}
& 2 \mathrm{a}_{0} \frac{\partial^{2} \mathrm{~h}}{\partial \mathrm{t}^{2}}+\beta_{1}\left(\mathrm{a}_{0}+\mathrm{a}_{1}\right) \frac{\partial \mathrm{h}}{\partial \mathrm{t}}=\frac{(1+\mathrm{e})(1+\xi)}{\gamma} \beta_{1}[\operatorname{div}(\mathrm{K}(\mathrm{C}, \mathrm{N}, \mathrm{T}) \nabla \mathrm{h})- \\
& \left.-\sum_{\mathrm{i}=1}^{\mathrm{n}} \operatorname{div}\left(\mathrm{K}_{\mathrm{c}_{\mathrm{i}}} \nabla \mathrm{c}_{\mathrm{i}}\right)-\operatorname{div}\left(\mathrm{K}_{\mathrm{T}} \nabla \mathrm{T}\right)\right]+\frac{(1+\mathrm{e})(1+\xi)}{\gamma} \frac{\partial}{\partial \mathrm{t}}[\operatorname{div}(\mathrm{K}(\mathrm{C}, \mathrm{N}, \mathrm{T}) \nabla \mathrm{h})- \\
& \left.-\sum_{\mathrm{i}=1}^{\mathrm{n}} \operatorname{div}\left(\mathrm{K}_{\mathrm{c}_{\mathrm{i}}} \nabla \mathrm{c}_{\mathrm{i}}\right)-\operatorname{div}\left(\mathrm{K}_{\mathrm{T}} \nabla \mathrm{T}\right)\right]+\sum_{\mathrm{i}=1}^{\mathrm{n}} \frac{\varepsilon(1+\mathrm{e})(1+\xi)}{\rho_{\mathrm{i}} \gamma} \times \\
& \times\left[\beta_{1}\left[\sigma \frac{\partial \mathrm{c}_{\mathrm{i}}}{\partial \mathrm{t}}-\mathrm{e} \frac{\partial \mathrm{N}_{\mathrm{i}}}{\partial \mathrm{t}}\right]+\left[\sigma \frac{\partial^{2} \mathrm{c}_{\mathrm{i}}}{\partial \mathrm{t}^{2}}-\mathrm{e} \frac{\partial^{2} \mathrm{~N}_{\mathrm{i}}}{\partial \mathrm{t}^{2}}\right]\right], \mathrm{X} \in \Omega_{1} \cup \Omega_{2}, \mathrm{t}>0, \mathrm{i}=\overline{1, \mathrm{n} ;}
\end{aligned}
$$

- the Laplace equation in erosion zone

$$
\Delta \mathrm{h}(\mathrm{X}, \mathrm{t})=0, \mathrm{X}=(\mathrm{x}, \mathrm{y}) \in \Omega_{3}, \mathrm{t}>0
$$

- mass transfer equation

$\operatorname{div}\left(\mathrm{D}_{\mathrm{T}}^{(\mathrm{i})} \nabla \mathrm{T}\right)+\operatorname{div}\left(\mathrm{D}^{(\mathrm{i})} \nabla \mathrm{c}_{\mathrm{i}}\right)-\left(\mathrm{u}, \nabla \mathrm{c}_{\mathrm{i}}\right)=\sigma \frac{\partial \mathrm{c}_{\mathrm{i}}}{\partial \mathrm{t}}+\frac{\partial \mathrm{N}_{\mathrm{i}}}{\partial \mathrm{t}}$,

$\mathrm{X} \in \Omega_{1} \cup \Omega_{2}, \mathrm{t}>0, \mathrm{i}=\overline{1, \mathrm{n}}$;

- mass transfer equation in erosion zone

$\operatorname{div}\left(\mathrm{D}_{\mathrm{T}}^{(\mathrm{i})} \nabla \mathrm{T}\right)+\operatorname{div}\left(\mathrm{D}^{(\mathrm{i})} \nabla \mathrm{c}_{\mathrm{i}}\right)=0, \mathrm{X} \in \Omega_{3}, \mathrm{t}>0, \mathrm{i}=\overline{1, \mathrm{n}} ;$

- mass transfer kinetics equation

$\frac{\partial N_{i}}{\partial t}=-\gamma_{i}\left(C_{m}^{(i)}(C, N, T)-c_{i}\right) N_{i}^{\alpha_{i}}$,

$\mathrm{X} \in \Omega_{1} \cup \Omega_{2}, \mathrm{t}>0, \mathrm{i}=\overline{1, \mathrm{n}}$;

- heat transfer equation

$\operatorname{div}(\lambda \nabla \mathrm{T})-\rho \mathrm{c}_{\mathrm{p}}(\mathrm{u}, \nabla \mathrm{T})=\mathrm{c}_{\mathrm{T}} \frac{\partial \mathrm{T}}{\partial \mathrm{t}}, \mathrm{X} \in \Omega_{1} \cup \Omega_{2}, \mathrm{t}>0 ;$

- heat transfer equation in erosion zone

$\operatorname{div}(\lambda \nabla \mathrm{T})=0, \mathrm{X} \in \Omega_{3}, \mathrm{t}>0$

- filtration law

$$
\mathrm{u}-\mathrm{ev}=-\mathrm{K}(\mathrm{C}, \mathrm{N}, \mathrm{T}) \nabla \mathrm{h}+\sum_{\mathrm{i}=1}^{\mathrm{n}} \mathrm{K}_{\mathrm{c}_{\mathrm{i}}} \nabla \mathrm{c}_{\mathrm{i}}+\mathrm{K}_{\mathrm{T}} \nabla \mathrm{T},
$$

$\mathrm{X} \in \bar{\Omega}, \mathrm{t} \geq 0$

- initial conditions

$$
\begin{aligned}
& \mathrm{h}(\mathrm{X}, 0)=\mathrm{H}_{0}(\mathrm{X}), \frac{\partial \mathrm{h}(\mathrm{X}, 0)}{\partial \mathrm{t}}=0, \mathrm{X} \in \bar{\Omega} ; \\
& \mathrm{c}_{\mathrm{i}}(\mathrm{X}, 0)=\mathrm{C}_{0}^{(\mathrm{i})}(\mathrm{X}), \mathrm{X} \in \bar{\Omega}, \mathrm{i}=\overline{1, \mathrm{n}} ; \\
& \mathrm{N}_{\mathrm{i}}(\mathrm{X}, 0)=\mathrm{N}_{\mathrm{i}}^{(0)}(\mathrm{X}), \mathrm{X} \in \bar{\Omega}, \mathrm{i}=\overline{1, \mathrm{n}} ; \\
& \mathrm{T}(\mathrm{X}, 0)=\mathrm{T}_{0}(\mathrm{X}), \mathrm{X} \in \bar{\Omega} ;
\end{aligned}
$$

- boundary conditions for heads

$$
\begin{aligned}
& \left.\mathrm{h}(\mathrm{X}, \mathrm{t})\right|_{\Gamma_{1} \cup \Gamma_{0}}=\mathrm{y}, \quad \mathrm{X} \in \Gamma_{1} \cup \Gamma_{0}, \\
& \left.\mathrm{~h}(\mathrm{X}, \mathrm{t})\right|_{\Gamma_{2}}=\mathrm{H}_{2}(\mathrm{X}, \mathrm{t}), \quad \mathrm{X} \in \Gamma_{2}, \\
& \left.\mathrm{~h}(\mathrm{X}, \mathrm{t})\right|_{\Gamma_{9}}=\mathrm{H}_{2}(\mathrm{X}, \mathrm{t}), \quad \mathrm{X} \in \Gamma_{9}, \\
& \left.(\nabla \mathrm{h}, \mathrm{n})\right|_{\Gamma_{10}}=0, \quad \mathrm{X} \in \Gamma_{10},\left.\quad(\nabla \mathrm{h}, \mathrm{n})\right|_{\Gamma_{3}}=0, \quad \mathrm{X} \in \Gamma_{3}, \\
& \left.\mathrm{~h}(\mathrm{X}, \mathrm{t})\right|_{\Gamma_{4}}=\mathrm{H}_{1}(\mathrm{X}, \mathrm{t}), \quad \mathrm{X} \in \Gamma_{4}, \\
& \left.\mathrm{~h}(\mathrm{X}, \mathrm{t})\right|_{\Gamma_{7}}=\mathrm{H}_{1}(\mathrm{X}, \mathrm{t}), \\
& \mathrm{X} \in \Gamma_{7},\left.(\nabla \mathrm{h}, \mathrm{n})\right|_{\Gamma_{3}}=0, \quad \mathrm{X} \in \Gamma_{3},
\end{aligned}
$$




$$
\begin{gathered}
\left.(\nabla h, n)\right|_{\Gamma_{5}}=0, X \in \Gamma_{5},\left.(\nabla h, n)\right|_{\Gamma_{6}}=0, X \in \Gamma_{6}, \\
h(x, y)=z, X \in \Gamma_{12},[h(x, y)]=0, X \in \Gamma_{11},
\end{gathered}
$$

for the concentration of salts

$$
\begin{aligned}
& \left.\left(D^{(i)} \nabla c_{i}+D_{T}^{(i)} \nabla T, n\right)\right|_{\Gamma_{0} \cup \Gamma_{1}}=0, X \in \Gamma_{0} \cup \Gamma_{1}, i=\overline{1, n}, \\
& \left.c_{i}(X, t)\right|_{\Gamma_{2}}=C_{1}^{(i)}(X, t), X \in \Gamma_{2}, i=\overline{1, n}, \\
& \left.c_{i}(X, t)\right|_{\Gamma_{9}}=C_{1}^{(i)}(X, t), X \in \Gamma_{9}, i=\overline{1, n}, \\
& \left.\left(\nabla c_{i}, n\right)\right|_{\Gamma_{10}}=0, X \in \Gamma_{10}, i=\overline{1, n}, \\
& \left.\left(\nabla c_{i}, n\right)\right|_{\Gamma_{3}}=0, X \in \Gamma_{3}, i=\overline{1, n}, \\
& \left.c_{i}(X, t)\right|_{\Gamma_{4}}=C_{m}^{(i)}(X, t), X \in \Gamma_{4}, i=\overline{1, n}, \\
& \left.c_{i}(X, t)\right|_{\Gamma_{7}}=C_{m}^{(i)}(X, t), X \in \Gamma_{7}, i=\overline{1, n}, \\
& \left.\left(\nabla c_{i}, n\right)\right|_{\Gamma_{8}}=0, X \in \Gamma_{8}, i=\overline{1, n}, \\
& \left.\left(\nabla c_{i}, n\right)\right|_{\Gamma_{5}}=0, X \in \Gamma_{5}, i=\overline{1, n}, \\
& \left.\left(\nabla c_{i}, n\right)\right|_{\Gamma_{6}}=0, X \in \Gamma_{6}, i=\overline{1, n}, \\
& \frac{\partial c_{i}}{\partial n}=0, \quad X \in \Gamma_{12},\left[c_{i}(x, y)\right]=0, \\
& X \in \Gamma_{11}, i=\overline{1, n},
\end{aligned}
$$

for temperature

$$
\begin{aligned}
& \left.\mathrm{T}(\mathrm{X}, \mathrm{t})\right|_{\Gamma_{0} \cup \Gamma_{1} \cup \Gamma_{2} \cup \Gamma_{9}}=\mathrm{T}_{\mathrm{atm}}(\mathrm{X}, \mathrm{t}), \mathrm{X} \in \Gamma_{0} \cup \Gamma_{1} \cup \Gamma_{2} \cup \Gamma_{9}, \\
& \left.(\nabla \mathrm{T}, \mathrm{n})\right|_{\Gamma_{3}}=0, \mathrm{X} \in \Gamma_{3},\left.\mathrm{~T}(\mathrm{X}, \mathrm{t})\right|_{\Gamma_{4}}=\mathrm{T}_{1}(\mathrm{X}, \mathrm{t}), \mathrm{X} \in \Gamma_{4}, \\
& \left.\mathrm{~T}(\mathrm{X}, \mathrm{t})\right|_{\Gamma_{7}}=\mathrm{T}_{1}(\mathrm{X}, \mathrm{t}), \mathrm{X} \in \Gamma_{7},\left.(\nabla \mathrm{T}, \mathrm{n})\right|_{\Gamma_{8}}=0, \mathrm{X} \in \Gamma_{8}, \\
& \left.(\nabla \mathrm{T}, \mathrm{n})\right|_{\Gamma_{10}}=0, \mathrm{X} \in \Gamma_{10},\left.(\nabla \mathrm{T}, \mathrm{n})\right|_{\Gamma_{5}}=0, \mathrm{X} \in \Gamma_{5}, \\
& \left.(\nabla \mathrm{T}, \mathrm{n})\right|_{\Gamma_{6}}=0, \quad \mathrm{X} \in \Gamma_{6}, \\
& \left.(\nabla \mathrm{T}, \mathrm{n})\right|_{\Gamma_{12}}=0, \quad \mathrm{X} \in \Gamma_{12}, \quad[\mathrm{~T}(\mathrm{x}, \mathrm{y})]=0, \quad \mathrm{X} \in \Gamma_{11},
\end{aligned}
$$

where $h$ is the head in the porous fluid; $c_{i}, N_{i}$ is the concentration of a multicomponent chemical solution in the liquid and solid phases; $\mathrm{T}$ is the temperature; $\mathrm{u}$ is the filtration velocity vector; $\mathrm{K}(\mathrm{C}, \mathrm{N}, \mathrm{T})$ is the filtration coefficient tensor; $\mathrm{K}_{\mathrm{ci}}$ is the chemical osmosis coefficients tensor; $\mathrm{K}_{\mathrm{T}}$ is the thermal osmosis coefficients tensor; $\mathrm{D}^{(\mathrm{i})}, \mathrm{D}_{\mathrm{T}}$ are the convection diffusion and thermal diffusion coefficients tensor; $\lambda$ is the tensor of coefficients of effective thermal conductivity of moist soil; $\rho$ is the density of porous solution; $c_{\rho}$ is the specific heat capacity of porous solution; $\mathrm{c}_{\mathrm{T}}$ is the volumetric heat capacity of soil; $\mathrm{C}_{\mathrm{m}}$ is the concentration of saturation limit of chemical substances in the liquid phase; $\sigma$ is the porosity of soil.

Free surface $\Gamma_{0}$ (depression curve) is described by relation [8]

$$
\phi(\mathrm{X}, \mathrm{t})=\left.(\mathrm{y}-\mathrm{h}(\mathrm{X}, \mathrm{t}))\right|_{\Gamma_{0}}=0
$$

and kinematic boundary condition is satisfied on it [8]

$$
\left.(\mathrm{u}, \mathrm{n})\right|_{\Gamma_{0}}=\sigma \frac{\partial \phi}{\partial \mathrm{t}}
$$

In the process of compaction of the soil, by reducing the porosity, the upper limit of soil will sink. That is, coordinates of the upper limit of soil will change over time. That is why we assign the kinematic boundary condition at this border, which allows us at any point in time to determine the position of this border

$$
\frac{\partial \mathrm{l}(\mathrm{x}, \mathrm{t})}{\partial \mathrm{t}}=\frac{2 \gamma \mathrm{a}}{(1+\mathrm{e})(1+\xi)} \int_{0}^{\mathrm{l}(\mathrm{x}, \mathrm{t})} \frac{\partial \mathrm{h}}{\partial \mathrm{t}} \mathrm{dx}, \mathrm{l}(\mathrm{x}, 0)=\mathrm{l}_{0}(\mathrm{x}) .
$$

Here $y=l(x, t)$ is the equation of the upper movable border of the soil. To simplify, the kinematic boundary condition (18) does not take into account the creep of soil skeleton.

The mathematical model (1)-(18) considers the possibility of the filtration destruction of the body of an earth dam [3], as well as the influence of anthropogenic factors - temperature and multicomponent chemical solutions [9]. Equation (1) describes a change in the excess heads in the porous fluid of the body of a dam and it is derived in article [3]

The stated problem is a nonlinear boundary problem for the system of elliptical-parabolic equations in the domains with free borders. The study of such problems in terms of correctness is given, for example, in paper [10]. However, the given study considered a one-dimensional case only, and, in addition, it did not take into account the existence of an erosion zone.

The nonlinearity of the constructed mathematical models requires the application of numerical methods for the approximate solution of the corresponding boundary problems. Among such methods, we shall note the finite element method (FEM) $[8,11]$ and a large group of grid-free methods, which include, for example, the method of radial basis functions (RBF) [11-15]. Note that the scientific literature reports the research into accuracy of the RBF method only for certain boundary problems (for example, articles [14, 15]). At present, the only research tool of boundary problems is a computational experiment - comparing the solutions by the RBF method with the solutions by other methods, sufficiently substantiated theoretically (for example, FEM), as was demonstrated in paper [11].

The stated problem is a nonlinear boundary problem for the system of elliptically-parabolic equations in the domains with free borders. The study of such problems in terms of correctness is given, for example, in paper [10]. However, the given study considered a one-dimensional case only, and, in addition, it did not take into account the existence of an erosion zone.

The authors of present research take into account the presence of a conduit in the body of a dam and an erosion zone in a two-dimensional case, formed as a result of its destruction. We also considered the impact of anthropogenic factors.

\section{The aim and tasks of the study}

The aim of present work is to predict the operation of HTC under condition of damage in a conduit by the methods of mathematical and computer modeling. The work's aim of prediction includes predictive values of heads and 
their gradients in the body of a dam in different moments, as well as the level of free surface. In addition, we shall take into account the impact of physical-chemical factors on the above-mentioned predictive values. lated:

To achieve the set aim, the following tasks were formu-

- to build a mathematical model of the filtration consolidation of the body of an earth dam with a conduit taking into account the influence of anthropogenic factors (temperature, concentration of chemical substances in the liquid and solid components);

- to consider creation of an erosion zone as a result of damaging a part of the conduit;

- to find numerical solutions of the corresponding nonlinear boundary problem, which describes the constructed mathematical model, by the RBF method;

- to implement a software realization of the proposed algorithms using the technology of OOP (to develop a corresponding software application that will make it possible not to conduct field experiments). To perform a number of computational experiments and to run their analysis.

\section{Consideration of the saturated-unsaturated filtration}

As a result of breaking down the pipeline, there was formed a free surface at the level of underground water (depression curve) $\Gamma_{0}$, which is a boundary between the regions of partial saturation (aeration area) above depression curve $\Gamma_{0}$ and complete saturation under $\Gamma_{0}$, filled with a filtration flow.

In the region of partial saturation, the process of moisture transfer is described by the following equation:

$$
\begin{aligned}
& \mu(\mathrm{h}) \frac{\partial \mathrm{h}}{\partial \mathrm{t}}=\operatorname{div}(\mathrm{K}(\mathrm{C}, \mathrm{N}, \mathrm{T}) \nabla \mathrm{h})- \\
& -\sum_{\mathrm{i}=1}^{\mathrm{n}} \operatorname{div}\left(\mathrm{K}_{\mathrm{c}_{\mathrm{i}}} \nabla \mathrm{c}_{\mathrm{i}}\right)-\operatorname{div}\left(\mathrm{K}_{\mathrm{T}} \nabla \mathrm{T}\right), \quad \mathrm{X} \in \Omega_{4}, \mathrm{t}>0,
\end{aligned}
$$

where

$$
\mu(h)=\frac{\partial W}{\partial h}=\frac{\partial(\operatorname{a\rho g}(h+y)+b)}{\partial h}
$$

is moisture capacity function;

$$
\mathrm{h}=\frac{\mathrm{p}}{\rho \mathrm{g}}+\mathrm{y}
$$

is hydraulic potential (head);

$$
\mathrm{p}=\rho g(h+y)
$$

is fluid pressure;

$$
\mathrm{K}(\mathrm{h})=\frac{\mathrm{a}_{1}}{\mathrm{~b}_{1}+\mathrm{p}^{\alpha}}=\frac{\mathrm{a}_{1}}{\mathrm{~b}_{1}+[\rho \mathrm{g}(\mathrm{h}+\mathrm{y})]^{2}},
$$

is water permeability coefficient;

$$
\operatorname{div}\left(\mathrm{D}_{\mathrm{T}}^{(\mathrm{i})} \nabla \mathrm{T}\right)+\operatorname{div}\left(\mathrm{D}^{(\mathrm{i})} \nabla \mathrm{c}_{\mathrm{i}}\right)-\left(\mathrm{u}, \nabla \mathrm{c}_{\mathrm{i}}\right)=\sigma \frac{\partial \mathrm{c}_{\mathrm{i}}}{\partial \mathrm{t}}+\frac{\partial \mathrm{N}_{\mathrm{i}}}{\partial \mathrm{t}},
$$

$$
\begin{aligned}
& \mathrm{X} \in \Omega_{1} \cup \Omega_{2}, \mathrm{t}>0, \mathrm{i}=\overline{1, \mathrm{n}}, \\
& \frac{\partial \mathrm{N}_{\mathrm{i}}}{\partial \mathrm{t}}=-\gamma_{\mathrm{i}}\left(\mathrm{C}_{\mathrm{m}}^{(\mathrm{i})}(\mathrm{C}, \mathrm{N}, \mathrm{T})-\mathrm{c}_{\mathrm{i}}\right) \mathrm{N}_{\mathrm{i}}^{\alpha_{\mathrm{i}}}, \\
& \mathrm{X} \in \Omega_{1} \cup \Omega_{2}, \mathrm{t}>0, \quad \mathrm{i}=\overline{1, \mathrm{n}}, \\
& \operatorname{div}(\lambda \nabla \mathrm{T})-\rho \mathrm{c}_{\mathrm{p}}(\mathrm{u}, \nabla \mathrm{T})=\mathrm{c}_{\mathrm{T}} \frac{\partial \mathrm{T}}{\partial \mathrm{t}}, \mathrm{X} \in \Omega_{1} \cup \Omega_{2}, \mathrm{t}>0,
\end{aligned}
$$

$\rho$ is the fluid density, $g$ is the acceleration of free fall, $y$ is the vertical coordinate, directed upwards, $\alpha, a_{1}, b_{1}$ are the constants, determined experimentally [16].

At free surface $\Gamma_{0}$, function $\mathrm{h}(\mathrm{X}, \mathrm{t})$ satisfies the condition for the conjugation of heads $\left.[\mathrm{h}]\right|_{\Gamma_{0}}=0$. Also,

$$
\left.\left[\mathrm{c}_{\mathrm{i}}\right]\right|_{\Gamma_{0}}=0,\left.[\mathrm{~T}]\right|_{\Gamma_{0}}=0,\left.\left[\mathrm{q}_{\mathrm{c}_{\mathrm{i}}}\right]\right|_{\Gamma_{0}}=0,\left.\left[\mathrm{q}_{\mathrm{T}}\right]\right|_{\Gamma_{0}}=0,\left.[\mathrm{u}]\right|_{\Gamma_{0}}=0 .
$$

\section{1. Idea of a numerical method}

The idea of a grid-free method of radial basis functions (refer, for example, to [14], [15] and the bibliography on RBF presented there) is as follows: we cover the closure of the domain $\bar{\Omega}=\Omega \bigcup \Gamma$ by principal points $\left(\mathrm{x}_{\mathrm{j}}, \mathrm{y}_{\mathrm{j}}\right), \mathrm{j}=\overline{1, \mathrm{n}}$. In this case, any two points cannot coincide.

We cover the closure $\bar{\Omega}$ of region $\Omega$ by collocation points $\left(\mathrm{x}_{\mathrm{i}}, \mathrm{y}_{\mathrm{i}}\right), \mathrm{i}=\overline{1, \mathrm{~m}}$. Denote

$$
\omega=\left\{\mathrm{i}:\left(\mathrm{x}_{\mathrm{i}}, \mathrm{y}_{\mathrm{i}}\right) \in \Omega\right\}, \gamma_{\mathrm{k}}=\left\{\mathrm{i}:\left(\mathrm{x}_{\mathrm{i}}, \mathrm{y}_{\mathrm{i}}\right) \in \Gamma_{\mathrm{k}}\right\}, \mathrm{k}=\overline{0,4} .
$$

Introduce designations

$$
r_{i j}=\sqrt{\left(x_{i}-x_{j}\right)^{2}+\left(y_{i}-y_{j}\right)^{2}}, \quad j=\overline{1, n}, i=\overline{1, m}, m \geq n .
$$

We shall search for the approximation values of functions in the form

$$
\mathrm{z}(\mathrm{X}, \mathrm{t}) \approx \sum_{\mathrm{j}=1}^{\mathrm{n}} \mathrm{z}_{\mathrm{j}}(\mathrm{t}) \phi_{\mathrm{j}}\left(\mathrm{r}_{\mathrm{j}}, \varepsilon_{\mathrm{z}}\right)
$$

where $\varepsilon_{\mathrm{z}}$ is the form parameter, $\phi_{\mathrm{j}}=\phi\left(\mathrm{r}_{\mathrm{j}}, \varepsilon_{\mathrm{z}}\right)$ is the radial basis function that depends on the distance

$$
r_{j}=\sqrt{\left(x-x_{j}\right)^{2}+\left(y-y_{j}\right)^{2}}, \quad j=\overline{1, n}
$$

and form parameter $\left.\varepsilon_{\mathrm{z}}>0, \mathrm{z}_{\mathrm{j}}(\mathrm{t})\right), \mathrm{j}=\overline{1, \mathrm{n}}$ are the unknown coefficients to find the values of functions of heads, the concentration of salts in the liquid and solid phases and temperature, respectively, which depend on time only.

As a result of employing the method of collocation in points (on which the RBF method is based) to find the unknown coefficients, we obtain a Cauchy problem for the system of ordinary non-linear differential equations.

We shall not present here the form of this problem because of its bulky representation and since we set other objectives for the present article. More details on its form can be found in paper [11].

\section{2. Algorithm for finding the coordinates of points} of free surface

Free surface of the region will shift over time. That is, coordinates of the points at boundary $\Gamma_{0}$ will vary depending on the temporal layer. That is why we need the algorithm in order to find these coordinates in the appropriate moment. 
Through the discretization of equation (17), we obtain

$$
\left(\mathrm{u}^{(\mathrm{k})}, \mathrm{n}^{(\mathrm{k})}\right)=\sigma \frac{\phi^{(\mathrm{k}+1)}(\mathrm{X})-\phi^{(\mathrm{k})}(\mathrm{X})}{\tau},
$$

where $\phi^{(\mathrm{k}+1)}-\phi^{(\mathrm{k})}$ is the displacement of free boundary on the $\mathrm{k}$-th temporal layer in the direction of external normal. Next, we receive

$$
\begin{aligned}
& \phi^{(\mathrm{k}+1)}(\mathrm{X})-\phi^{(\mathrm{k})}(\mathrm{X})= \\
& =\frac{\tau}{\sigma}\left(\mathrm{u}_{\mathrm{x}}^{(\mathrm{k})}(\mathrm{X}) \mathrm{n}_{\mathrm{x}}^{(\mathrm{k})}(\mathrm{X})+\mathrm{u}_{\mathrm{y}}^{(\mathrm{k})}(\mathrm{X}) \mathrm{n}_{\mathrm{y}}^{(\mathrm{k})}(\mathrm{X})\right), \mathrm{X} \in \Gamma_{0},
\end{aligned}
$$

where $f^{(k)}(X)=f\left(X, t_{k}\right), t_{k}=\tau \cdot k, k=0,1,2, \ldots, \tau$ is the step of discretization over time.

\section{3. Algorithm for finding the coordinates of internal points}

Since when displacing the upper limit some internal points in the region may appear outside of the region, then it is necessary to implement an algorithm in order to compress internal points.

The best for this purpose is the compression of points by the magnitude, which is inversely proportional to the square of distance from the internal point to the nearest point of free border $\Gamma_{0}$. That is

$$
X_{i}^{(k+1)}=X_{i}^{(k)}+\frac{\left(\phi_{j}^{(k+1)}-\phi_{j}^{(k)}\right)}{r\left(X_{i}^{(k)}, X_{j}^{(k)}\right)^{2}}, i \in \omega,
$$

where

$$
\begin{aligned}
& \min _{\mathrm{p} \in \gamma_{0}}\left(r\left(X_{i}^{(\mathrm{k})}, X_{\mathrm{p}}^{(\mathrm{k})}\right)\right)=r\left(X_{\mathrm{i}}^{(\mathrm{k})}, X_{\mathrm{j}}^{(\mathrm{k})}\right), j \in \gamma_{0}, \\
& r\left(X_{\mathrm{i}}^{(\mathrm{k})}, X_{\mathrm{j}}^{(\mathrm{k})}\right)=\sqrt{\left(\mathrm{x}_{\mathrm{i}}-\mathrm{x}_{\mathrm{j}}\right)^{2}+\left(\mathrm{y}_{\mathrm{i}}-\mathrm{y}_{\mathrm{j}}\right)^{2}} .
\end{aligned}
$$

\section{Results of numerical experiment}

In order to solve the set problem, we developed an appropriate software application in the integrated programming environment Microsoft Visual Studio 2008 in the language C\#.

The benefit of software application is the use of standard tools and functions for building graphs. That is why the user is not required to install DirectX or OpenGL libraries.

We used a multi-quadratic radial basis function $\phi(\mathrm{r}, \varepsilon)=$ $=\sqrt{1+(\mathrm{r} \varepsilon)^{2}}$ for numerical experiments with a parameter of form $\varepsilon=10^{-7}$; the number of nodal and colocated points equals 293. The process was investigated for 360 days, at the 10-day step in time.

We obtained the values of temperature, the concentration of salts and gypsum in the solid and liquid phases, and the heads over the period of 360 days, which can be shown graphically (Fig. 2-6).

Numerical experiments demonstrate that the existence of erosion zone in the body of a dam significantly affects the distribution of excess heads, especially in the erosion zone itself, where the head is much smaller. The difference in excess heads of an earth dam with a conduit and with a conduit and erosion zone is shown in Fig. 7. The presence of erosion zone in the body of a dam does not exert a significant impact on the concentration of salts in the liquid phase, it is only slightly reduced in the erosion zone itself, while the concentration of gypsum in the liquid phase will increase in the erosion zone. Regarding the temperature, one can draw a conclusion that the existence of erosion zone does not have a significant impact on the distribution of temperature in the erosion zone itself, however, the overall temperature across the entire dam slightly decreased. Experiments reveal that the presence of erosion zone in the body of a dam considerably affects the gradient of head. In the erosion zone, it becomes larger (maximum difference of about 2). The maximum relative difference between the distribution of excess heads in the body of a dam with a conduit and with a conduit and erosion zone is, respectively, about 71 \% (Fig. 8).

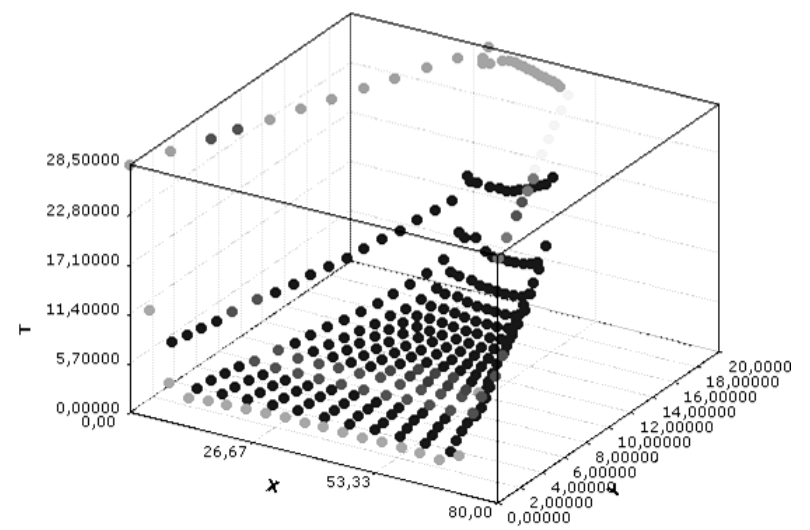

Fig. 2. Temperature distribution

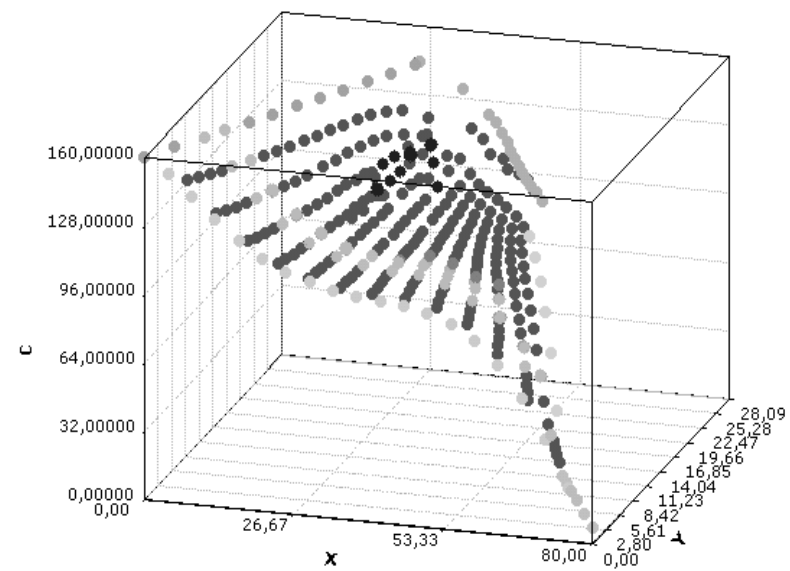

Fig. 3. Distribution of the concentration of salts in the liquid phase

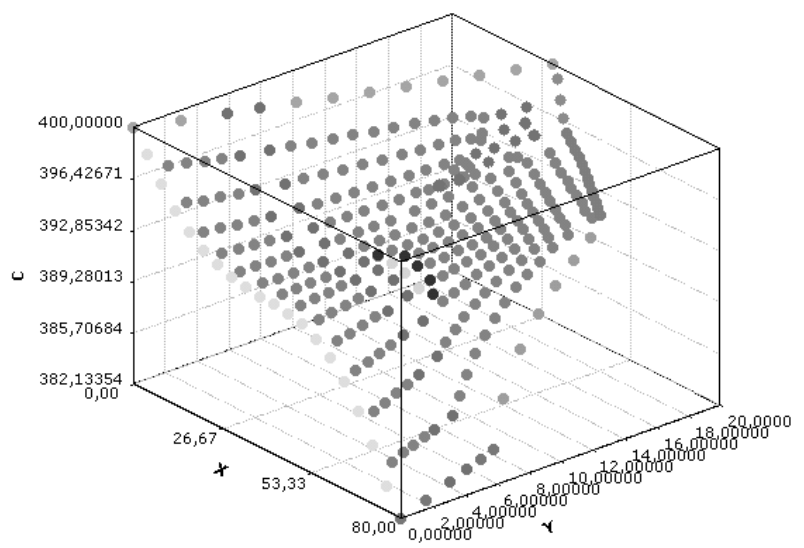

Fig. 4. Distribution of the concentration of salts in the solid phase 


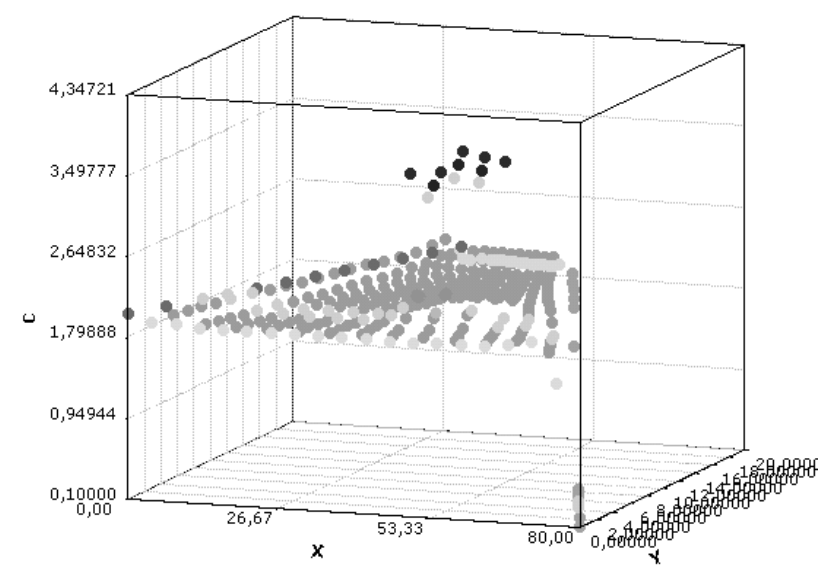

Fig. 5. Distribution of the concentration of gypsum in the liquid phase

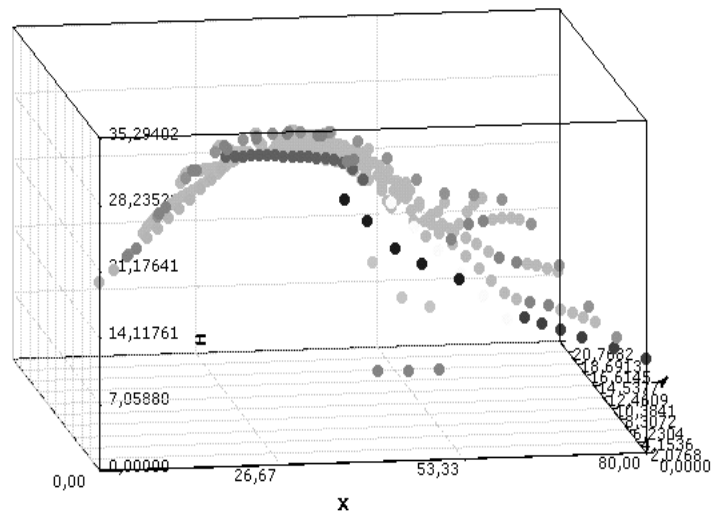

Fig. 6. Distribution of excess heads

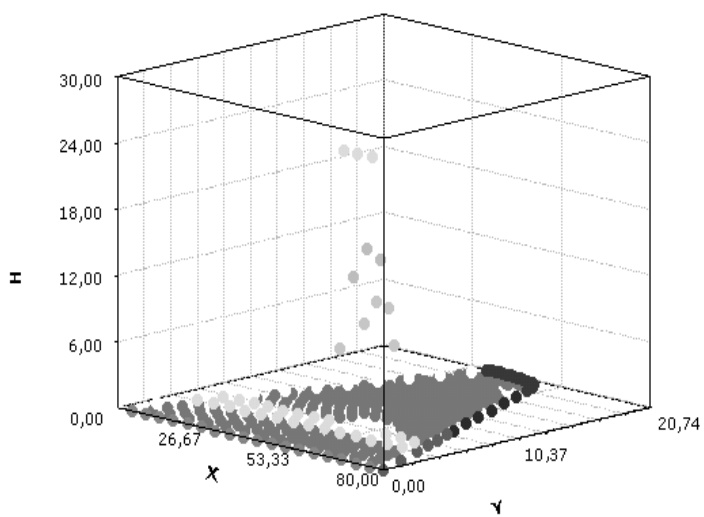

Fig. 7. Difference of excess heads in an earth dam with a conduit and with a conduit and erosion zone

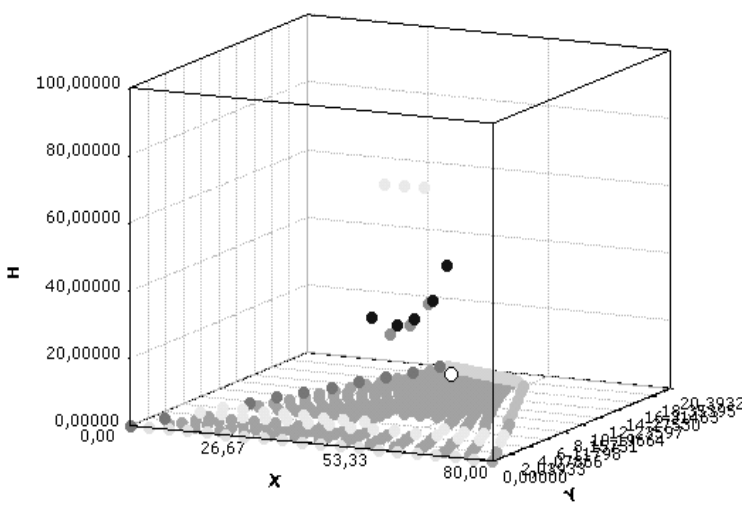

Fig. 8. Relative difference in the excess heads in an earth dam with a conduit and with a conduit and erosion zone

\section{Discussion of results of examining the filtration processes in the body of an earth dam}

The research conducted, although on the example of a modeling problem, demonstrate that in the process of designing and operation of earth dams, serious attention should be paid to the prediction of their (dams) work. This is due to the fact that the filtration processes that occur in the soil material of a dam significantly affect its failure-free operation. In addition, it may pose the economic, environmental, and humanitarian threat. Moreover, sometimes these processes (filtration and filtration consolidation) take place fast. That is why the tools of mathematical and computer modeling, which were employed in the present article, make it possible not only to assess the scale and consequences of possible damage, but also to provide their quantitative estimation. It saves considerable resources and time to conduct field experiments. Present study is the continuation of authors' research into the problems on filtration consolidation of earth dams with regard to anthropogenic factors [3], but without taking into account the existence in the body of a dam of engineering inclusions. The possible shortcoming of this study is that at this stage we consider a two-dimensional problem leaving the consideration of a three dimensional problem as a direction for further research of the authors. Erosion zone was also regarded as constant over time. That is why in the future we plan to solve a problem where the erosion zone dynamically changes.

It should be noted that, in general, the issue of examining the correctness of this problem's statement from the point of view of classical mathematics remains open and will form one of the directions of future research.

\section{Conclusions}

1. We built a mathematical model of the filtration consolidation of the body of an earth dam with a conduit taking into account the influence of physical-chemical factors. It is a non-linear boundary problem for the system of elliptic-parabolic equations in the domains with free borders. The mathematical model constructed includes a consideration of the existence in the body of the dam of engineering inclusions (culverts), the impact of anthropogenic factors and the compaction of an array of soil.

2. We considered the presence of an erosion zone (as a result of damage to the conduit). It was considered both in the construction of the mathematical model (the examined processes in the body of a dam and in the erosion zone are described by different equations) and in the construction of the body of a dam in the software. Taking into account the erosion zones produces a significant effect on the overall picture of filtration processes occurring in the body of a dam. In particular, the distribution of excess heads in the erosion zone itself is much smaller (maximum head drop to $6 \mathrm{~m}$ ). Experiments demonstrate that the existence of erosion zone in the body of a dam significantly affects the gradient of head. It grows larger in the erosion zone (maximum difference of about 2).

3. Numerical solutions of the corresponding nonlinear boundary problem, which is described by the mathematical model constructed, are found by the method of RBF. The very idea of the RBF method is described in present arti- 
cle. We also present a general form, which the solutions of the desired functions take. The form of the approximated solution for each particular desired function is found by its substitution in the presented general formula.

4. In order to solve the problem on filtration consolidation of an earth dam with a conduit and erosion zone, we developed appropriate software application that enables to carry out numerical experiments by varying the input data and parameters of the form, as well as represent results of these experiments in the form of charts and numerical data according to each temporal layer.

We performed experiments, which indicate that the existence of erosion zone leads to a sharp rise in the gradients of heads in this zone (maximum relative growth is $71 \%$ ). Such growth in the gradients of heads leads to an increase in the speed of porous fluid and, consequently, may lead to the increase in erosion zone and to the destruction of the body of the dam.

\section{References}

1. Foster, M. Use of event trees to estimate the probability of failure of embankment dams by internal erosion and piping [Text] / M. Foster // 20th Congress on Large Dams. - Beijing, 2000. - P. 237-259.

2. Malik, L. K. Emergency situations related to hydrotechnical construction [Text] / Л. К. Малик // Hydrotechnical construction. 2009. - Issue 12. - P. 2-16.

3. Vlasyuk, A. Numerical solution of problems of filtration consolidation and destruction of soils in terms of heat-mass transfer by radial basis functions method [Text] / A. Vlasyuk, P. Martyniuk. - Rivne: NUWMNRU, 2010. - 277 p.

4. Sellmeijer, J. B. Numerical computation of seepage erosion below dams (piping) [Text] / J. B. Sellmeijer // Proc. 3rd Int.Conf.Scour and Erosion. - Amsterdam, 2006. - 6 p.

5. Vlasyuk, A. P. Contact erosion and filtration consolidation of soils under conditions of heat-salt transfer [Text] / A. P. Vlasyuk, P. N. Martynyuk // Mathematical modeling. - 2012. - Vol. 24, Issue 11. - P. 97-112.

6. Vlasyuk, A. P. Numerical solution of three-dimensional problems of filtration consolidation with regard for the influence of technogenic factors by the method of radial basis functions [Text] / A. P. Vlasyuk, P. M. Martynyuk // Journal of Mathematical Sciences. - 2010. - Vol. 171, Issue 5. - P. 632-648. doi: 10.1007/s10958-010-0163-z

7. Vlasyuk, A. P. Mathematical Simulation of the Transport of Salt in the Case of Filtration and Moisture Transfer in SaturatedUnsaturated Soils in a Moistening Regime [Text] / A. P. Vlasyuk, T. P. Tsvetkova // Journal of Engineering Physics and Thermophysics. - 2015. - Vol. 88, Issue 5. - P. 1062-1073. doi: 10.1007/s10891-015-1285-4

8. Sergienko, I. Mathematical modeling and study of processes in inhomogeneous media [Text] / I. Sergienko, V. Skopetsky, V. Deineka. - Kyiv: Naukova Dumka, 1991. - 432 p.

9. Kutia, T. Mathematical modeling of wetting of the soil on the slope in conditions salt transfer [Text] / T. Kutia // Visnyk KNU. Ser.: Mathematical Modeling. Information Technology. Automated control systems. - 2014. - Issue 1105. - P. 99-110.

10. Martynyuk, P. M. Existence and uniqueness of a solution of the problem with free boundary in the theory of filtration consolidation of soils with regard for the influence of technogenic factors [Text] / P. M. Martynyuk // Journal of Mathematical Sciences. - 2015. Vol. 207, Issue 1. - P. 59-73. doi: 10.1007/s10958-015-2355-z

11. Martyniuk, P. Solution of boundary value problems for systems of quasi-linear parabolic equations by grid and meshfree numerical methods [Text] / P. Martyniuk // Siberian Electronic Mathematical Reports. - 2014. - Vol. 11. - P. 476-493.

12. Tolstyh, A. Meshless method based on radial basis functions [Text] / A. Tolstyh, D. Shirobokov // Computational Mathematics and Mathematical Physics. - 2005. - Vol. 45, Issue 8. - P. 1447-1454.

13. Biazar, J. Galerkin RBF for integro-differential eguations [Text] / J. Biazar, M. Asadi // British Journal of Mathematics and Computer Science. - 2015. - Vol. 11, Issue 2. - P. 1-9. doi: 10.9734/bjmcs/2015/19265

14. Franke, C. Solving partial differential equations by collocation using radial basis functions [Text] / C. Franke, R. Schaback // Applied Mathematics and Computation. - 1998. - Vol. 93, Issue 1. - P. 73-82. doi: 10.1016/s0096-3003(97)10104-7

15. Giesl, P. Meshless Collocation: Error Estimates with Application to Dynamical Systems [Text] / P. Giesl, H. Wendland // SIAM Journal on Numerical Analysis. - 2007. - Vol. 45, Issue 4. - P. 1723-1741. doi: 10.1137/060658813

16. Lukner, L. Modeling of geofiltration [Text] / L. Lukner, V. Shestakov. - Moscow: Nedra, 1976. - 407 p. 